[Agr. Biol. Chem., Vol. 29, No. 2, p. 151 156, 1965]

\title{
Syntheses of Pyridazine Derivatives as Herbicides
}

\section{Part II. Preparation of 3-Halo- and 3-Anilino-6-phenoxypyridazines}

\author{
By Teruomi Jojima and Saburo Tamura \\ Department of Agricultural Chemistry, The University of Tokyo, Tokyo \\ Received September 7, 1964
}

\begin{abstract}
Various 3-halo-6-phenoxypyridazines, with or without nitro groups on their benzene rings, and 3-anilino-6-phenoxypyridazines were prepared together with some related compounds to be evaluated as herbicides. Ultraviolet spectra of some nitrophenoxypyridazines thus obtained were also examined.
\end{abstract}

In the previous paper," it was reported that several pyridazyl phenyl ethers showed marked pre-emergent herbicidal activity to radish and millet. To extend the preceding studies on the structure-activity relationship of pyridazine derivatives, the authors prepared 3-halo-6-phenoxypyridazines, with or without nitro groups on their benzene rings, and 3anilino-6-phenoxypyridazines. The compounds obtained are shown in Tables I and II.

For the syntheses of 3-bromo-6-phenoxypyridazines, various phenols were treated with 3, 6-dibromopyridazine ${ }^{2)}$ in the presence of metallic sodium in boiling benzene or toluene according to the procedure described earlier. ${ }^{3)}$ However, 3-bromo-6-(2', 4'-dichlorophenoxy)and 3-bromo-6-(2', 6'-dichlorophenoxy)-pyridazines could not be obtained by this method, whereas the reaction in the presence of anhydrous potassium carbonate at $150 \sim 160^{\circ} \mathrm{C}$ without the solvent gave these compounds in fairly good yields respectively.

Syntheses of various anilinopyridazines including 3-chloro-6-anilino- and 3-anilino-6benzyloxy-pyridazines had been reported by Yoneda et al. ${ }^{4)}$ In the present study, several 3-anilino-6-phenoxypyridazines as well as 3-

1) S. Tamura and T. Jojima, This Journal, 27, 728 (1963). 2) J. Druey, Kd. Meier and K. Eichenberger, Helv. Chim. Acta, 37, 121 (1954);

3) S. Tamura and T. Jojima, This Journal, 27, 653 (1963). bromo-6-anilinopyridazines were prepared.

In syntheses of nitrophenoxypyridazines, the treatment of 6-chloro-3- $(2 \mathrm{H})$ pyridazone (I) with chloronitrobenzenes in the presence of the base was attempted at first, but this reaction did not occur and only starting materials were recovered. On the other hand, reaction of I with 2, 4-dinitro-chlorobenezene gave a product, which was supposed to be 6 chloro-2-( $2^{\prime}, \quad 4^{\prime}$-dinitrophenyl $)-3$-pyridazone having the structure II through the examination of infrared spectrum and elementary analysis.<smiles>O=c1ccc(Cl)n[nH]1</smiles><smiles>O=C(c1ccc(Cl)nn1)N1CCCC([N+](=O)[O-])C1</smiles>

Reaction of 3, 6-dihalopyridazines with nitrophenols in anhydrous condition gave the expected nitrophenoxypyridazines. Thus, equimolar amounts of the corresponding nitrophenol and halopyridazine were treated in the presence of anhydrous potassium carbonate at $150 \sim 160^{\circ} \mathrm{C}$ for about $15 \mathrm{~min}$. After initial vigorous reaction had ceased, the

4) F. Yoneda, T. Ohtaka and Y. Nitta, Chem. Pharm. Bull., 11740 (1963). 
reaction mixture usually became solid, which was cooled, washed with dilute aqueous alkali and recrystallized from appropriate solvent. Under this reaction condition, $m$-nitrophenol always gave expected mono-ethers in good yields, but a-nitrophenols reacted slowly to yield expected products in poor yields. Especially, the attempt to obtain ether from 2, 4dinitro-6-methylphenol was unsuccessful. The difficulty of $a$-nitrophenols to react with dichloropyridazines may be partly due to steric hyndrance by nitro groups in the benzene rings, as was previously observed in the reaction of o-chlorophenols with dichloropyridazine. ${ }^{2)}$

Recently, syntheses of 4- or 5-substituted pyridazines were reported by several workers, but none of corresponding phenoxypyridazines had been prepared. Kuraishi ${ }^{5)}$ obtained 4-ethoxy- 3, 6-dichloropyridazine (III) and 4-hydrazino-3, 6-dichloropyridazine (IV), by the reaction of sodium ethoxide or hydrazine with 3, 4, 6-trichloropyridazine, and pointed out that the chlorine atom at 4position of this trichloropyridazine is more reactive than those at 3 - and 6-positions.<smiles>CCOc1cc(Cl)nnc1Cl</smiles>

(III)<smiles>NNc1cc(Cl)nnc1Cl</smiles>

(IV)
In the present study, 3, 4, 6-trichloropyridazine was heated with nitrophenols and anhydrous potassium carbonate as in the case of the corresponding reaction of 3,6-dichloropyridazine. As shown in Table II, $m$-nitrophenoxy derivative was obtained in the best yield, whereas attempts to prepare $4-\left(2^{\prime}, 4^{\prime}\right.$ dinitrophenoxy)-3, 6-dichloropyridazine gave merely intractable tars.

As described in the previous report, "3chloro-6-phenoxypyridazines having methoxyl group at their benzene rings possess rather hige herbicidal activity. 4-(2'-Methoxy-

\footnotetext{
5) T. Kuraishi, Chem. Pharm. Bull., 4, 137 (1956); 5, 376
}

phenoxy)-3, 6-dichloropyridazine (V) was prepared by treating 3, 4, 6-trichloropyridazine with guaiacol in the presence of metallic sodium in the molar ratio of $1: 2: 1$ in refluxing benzene.<smiles>COc1ccccc1Oc1ccc(Cl)nn1</smiles>

(V)

Then the ultraviolet spectra of pyridazines: containing nitrophenoxy or methoxyphenoxy groups were examined in methanol and the results are shown in Figs. 1,2 and 3. As shown in these figures, $p$-nitrophenoxypyridazines such as 3-chloro-6-(4'-nitrophenoxy)- and 4-(4'-nitrophenoxy)-3,6-dichloropyridazines exhibit large shifts of absorption maxima to longer wave length as compared with those of corresponding $a$ - and $m$-nitrophenoxy derivatives. More-

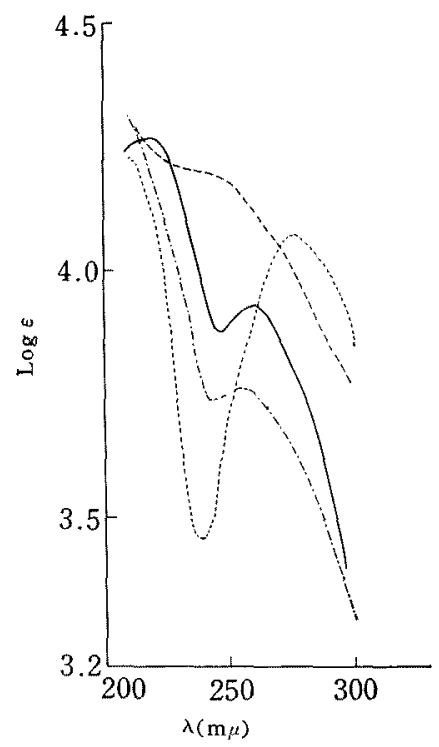

FIG. 1. Ultraviolet Spectra of 3-Chloro-6-nitrophenoxypyridazines (in $\mathrm{MeOH}$ ).

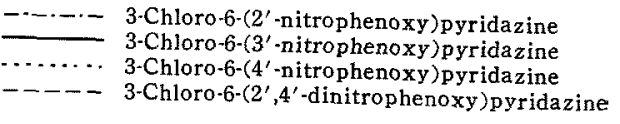




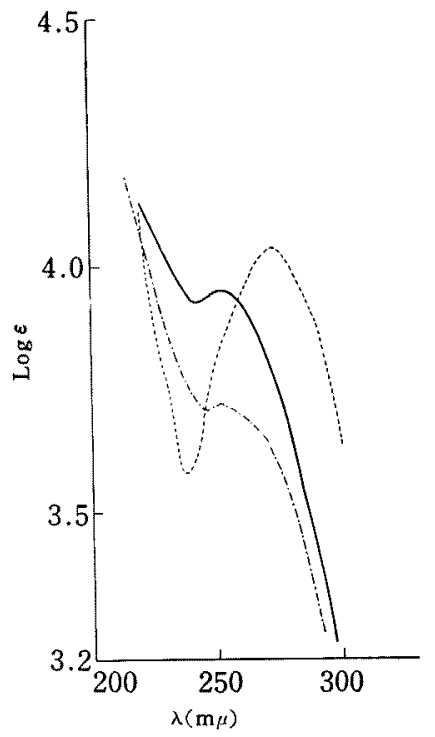

FIG. 2. Ultraviolet Spectra of 4-Nitrophenoxy3,6-dichloropyridazines (in $\mathrm{MeOH}$ ).

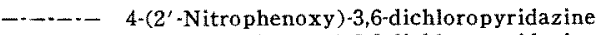
........ 4-( 4 - $4^{\prime}$-Nitrophenoxy)-3,6-dichloropyridazine

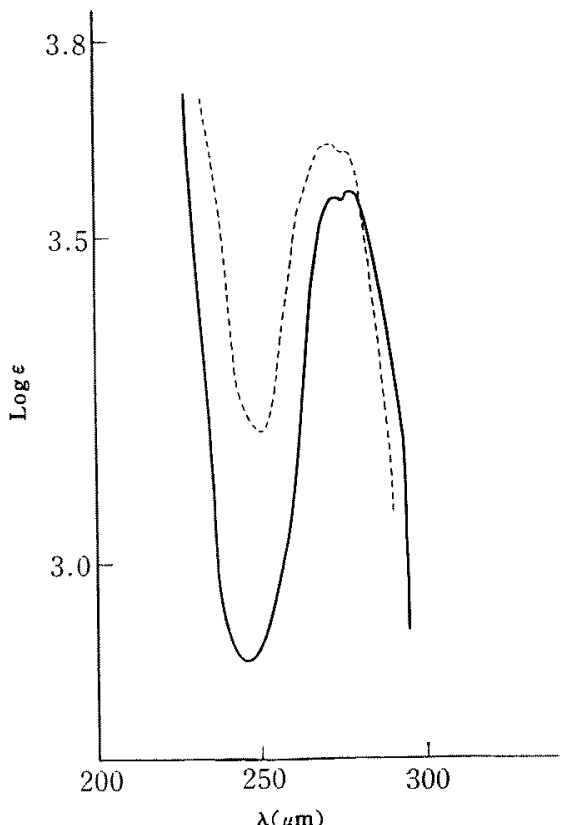

FIG. 3. Ultraviolet Spectra of Methoxyphenoxypyridazines (in $\mathrm{MeOH}$ ).

3-Chloro-6-(2'-methoxyphenoxy)pyridazine 4-(2'-Methoxyphenoxy)-3,6-dichloropyridazine over, the former derivatives show stronger absorption intensity. Concerning the relation between absorption maxima and position of nitrophenoxy group in pyridazine ring, it was found that compounds of 6-substituted series show the maxima of a little longer wave length than those of 4-substituted series. Among 6-substituted compounds, 3-chloro-6$\left(2^{\prime}, 4^{\prime}\right.$-dinitrophenoxy)pyridazine has no absorption maximum, showing only a shoulder at $240 \mathrm{~m} \mu$. As for methoxyphenoxypyridazines, 3-chloro-6-(2'-methoxyphenoxy)pyridazine has a doublet with maxima at $273 \mathrm{~m} \mu$. and $277 \mathrm{~m} \mu$, one of which is observed as a shoulder in the case of 4-(2'-methoxyphenoxy $)-3$, 6-dichloropyridazine.

Herbicidal activities of these pyridazine derivatives will be reported later.

\section{EXPERIMENTAL}

Melting points are uncorrected. The ultraviolet absorption stectra were taken in methanol with Cary 14-PM spectrophotometer. For the preparation of compounds, only typical runs are described in this part.

3-Bro mo-6-( $2^{\prime}$-methox y phenox y)pyridazine.

A mixture of $26.0 \mathrm{~g}$ (0.21 mole) of guaiacol $1.15 \mathrm{~g}(0.50 \mathrm{~mole})$ of metallic sodium and $40 \mathrm{ml}$ of toluene was heated to reflux. After the phenolate was formed, $10.0 \mathrm{~g}$ ( 0.04 mole) of 3,6-dibromopyridazine was added to the mixture, and refluxing continued for additional $4 \mathrm{hrs}$. After cooling, the reaction mixture was transferred into a 11 . separating funnel along with ca. $600 \mathrm{ml}$ of $2 \mathrm{~N}$ aqueous sodium hydroxide and $160 \mathrm{ml}$ of toluene, and the funnel was shaken vigorously. The toluene layer separated was washed with three portions of $300 \mathrm{ml}$ of water and dried over anhydrous potassium carbonate. After removal of toluene under reduced pressure, the oily residue was dried in a vacuum desiccator. The crude crystalline solid was recrystallized from ethanol to yield $11.0 \mathrm{~g}$ of colorless prisms, m.p., $121 \sim$ $122^{\circ} \mathrm{C}$.

\section{3-Bromo-6-(2', $6^{\prime}$-dichlorophenoxy $)$ pyridazine.}

Five grams (0.02 mole) of 3,6-dibromopyridazine, $3.4 \mathrm{~g}(0.02 \mathrm{~mole})$ of 2,6-dichlorophenol and $2.9 \mathrm{~g}$ ( 0.02 mole) of anhydrous potassium carbonate were throughly mixed and heated at $150 \sim 160^{\circ} \mathrm{C}$ in an oil 


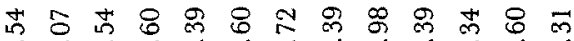

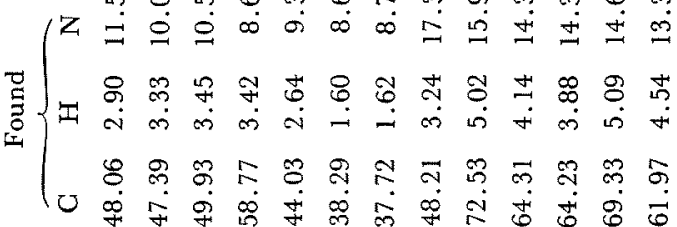

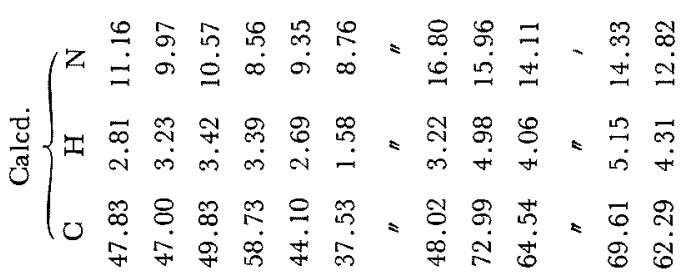

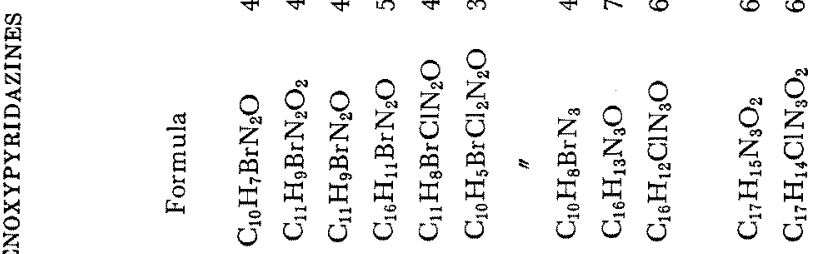

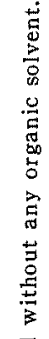

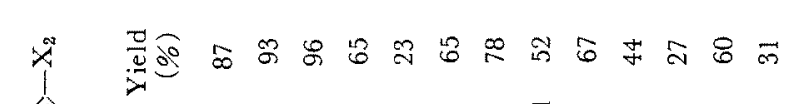

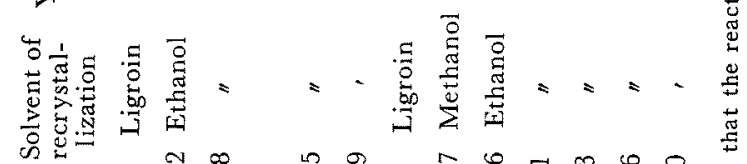

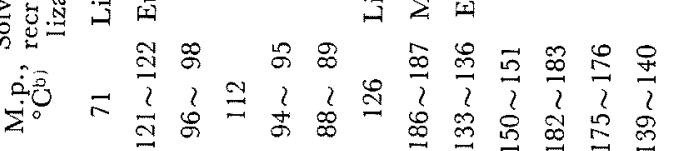

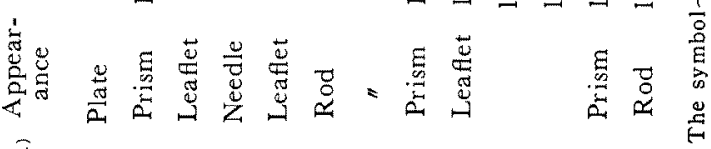

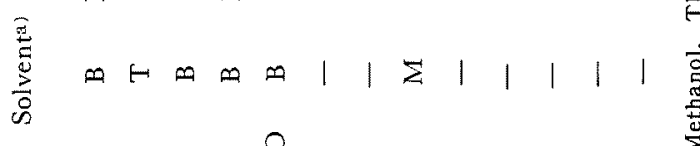

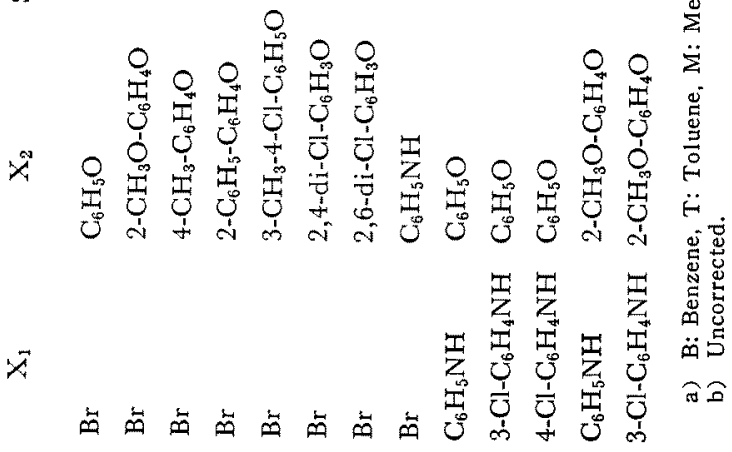




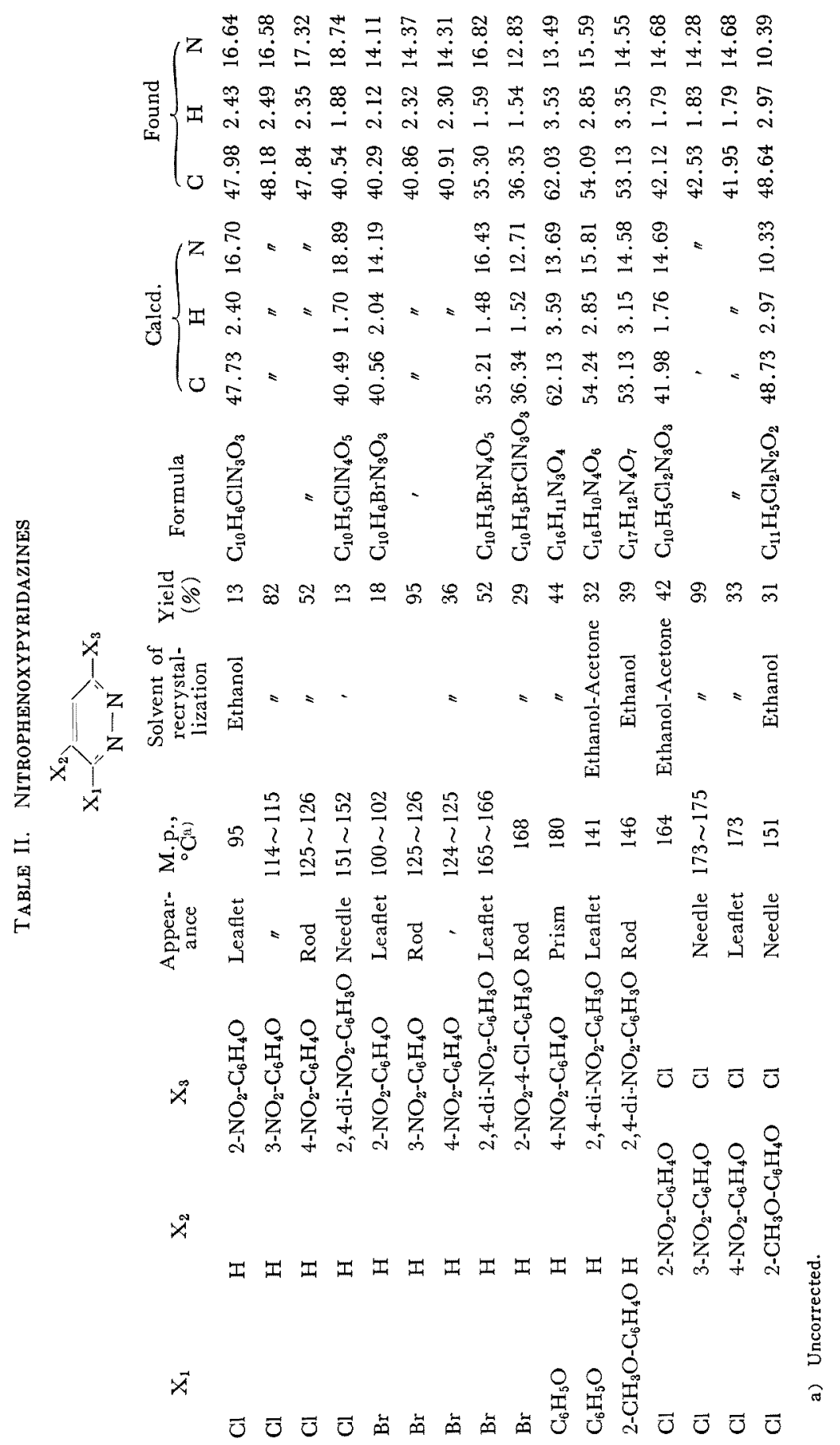


bath for 15 mins. After cooling, the residue was washed with dilute sodium hydroxide solution and water successively, and then recrystallized from ligroin to yield colorless rods, m.p. $126^{\circ} \mathrm{C}$.

\section{3-Anilino-6-phenox ypyridazine.}

A mixture of $50 \mathrm{~g}$ (about nine times of the theoretical amount) of phenol, and $1.5 \mathrm{~g}(0.07 \mathrm{~mole})$ of metallic sodium was heated in an oil bath to give the phenolate, to which was added $10.0 \mathrm{~g}(0.05$ mole $)$ of 3-chloro-6-anilinopyridazine. The heating was further continued at $180 \sim 200^{\circ} \mathrm{G}$ for $4 \mathrm{hrs}$. After removal of excess phenol under reduced pressure, the residue was extracted with three portions of 200 $\mathrm{ml}$ of ether. The combined ethre solution was washed with dilute sodium hydroxide solution and water successively, and dried over anhydrous potassium carbonate. After evaporation of ether, the residue was recrystallized from ethanol giving colorless needles, m.p. $149^{\circ} \mathrm{C}$.

\section{3-Chloro-6-(3'-nitrophenoxy)- and $3,6-\mathrm{Bis}\left(3^{\prime}\right.$-nitro- phenoxy)-pyridazines.}

A mixture of $20.0 \mathrm{~g}$ ( 0.13 mole) of 3,6-dichloropyridazine, $28.1 \mathrm{~g}$ ( 0.13 mole) of $m$-nitrophenol and $17.9 \mathrm{~g}$ ( 0.13 mole) of anhydrous potassium carbonate was treated as described for the preparation of 3-bromo6-(2',6'-dichlorophenoxy)pyridazine. After recrystallization from ethanol, there was obtained $26.8 \mathrm{~g}$ of colorless leaflets, m.p. $114 \sim 115^{\circ} \mathrm{C}$.

The mixture was heated for $1 \mathrm{hr}$ to give the bisether, 3,6-bis(3'-nitrophenoxy)pyridazine, along with the mono-ether. Thus, starting from $20.0 \mathrm{~g}$ of 3,6 -dichloropyridazine, $7 \mathrm{~g}$ of bis-ether and $8 \mathrm{~g}$ of monoether were obtained. The bis-ether melts at $162^{\circ} \mathrm{C}$, after repeated recrystallization from ethanol-acetone. Anal. Found: C, 54.16; H. 2.81; N, 15.97. Calcd. for $\mathrm{C}_{16} \mathrm{H}_{10} \mathrm{~N}_{4} \mathrm{O}_{6}: \mathrm{C}, 54.24 ; \mathrm{H}, 2.85 ; \mathrm{N}, 15.82 \%$.

3 - Phenoxy - $6-\left(4^{\prime}\right.$-nitrophenoxy) pyridazine, 4 - (3'nitrophenoxy)-3,6-dichloropyridazine and related compounds were prepared by the same procedure as described for the synthesis of 3-bromo-6- $\left(2^{\prime}, 6^{\prime}-\mathrm{di}\right.$ chlorophenoxy)pyridazine.

6-Chloro-2-(2',4'-dinitrophenyl)-3-pyridazone.

A mixture of $5.0 \mathrm{~g}(0.04$ mole) of 6 -chloro-3- $(2 \mathrm{H})$ - pyridazone, $7.7 \mathrm{~g}(0.04 \mathrm{~mole})$ of 2,4-dinitro-chlorobenzene, and $23 \mathrm{ml}$ of $10 \%$ aqueous potassium hydro. xide solution was heated at $80^{\circ} \mathrm{C}$ for $5 \mathrm{hrs}$ with stirring. The resulted yellowish crystals were washed with water and dried. Recrystallization from ethanol gave $2 \mathrm{~g}$ of slightly yellowish fine needles, m.p. $167^{\circ} \mathrm{C}$. The infrared spectrum shows strong $\mathrm{C}=\mathrm{O}$ band at $1680 \mathrm{~cm}^{-1}$ as well as strong $\mathrm{NO}_{2}$ bands at 1351 and $1551 \mathrm{~cm}^{-1}$. Anal. Found; C, 40.46; H, 1.91; $\mathrm{N}$, 19.01. Calcd. for $\mathrm{C}_{10} \mathrm{H}_{5} \mathrm{ClN}_{4} \mathrm{O}_{5}: \mathrm{C}, 40.49 ; \mathrm{H}$, 1.70: N, $18.89 \%$. From these results this product was proved to be 6-chloro-2-( $\left(2^{\prime}, 4^{\prime}\right.$-dinitrophenyl $)-3$ pyridazone.

\section{4-(2'-Methoxyphenoxy)-3,6-dichloropyridazine}

A mixture of $22.1 \mathrm{~g}$ ( 0.18 mole) of guaiacol, $2.1 \mathrm{~g}$ ( 0.09 mole) of metallic sodium and $40 \mathrm{ml}$ of benzene was heated to reflux. After phenolate was formed, $15 \mathrm{~g}$ (0.08 mole) of 3,4,6-trichloropyridazine was added to the mixture, and refluxing continued for additional 2 hrs. After cooling, the crystalline solid separated were filtered off and washed with ether. After recrystallization from ethanol, there was obtained $2.0 \mathrm{~g}$ of fine needles. The benzene flitrate was washed with dilute aqueous sodium hydroxide and water successively, and dried over anhydrous sodium sulfate. Benzene was removed under reduced pressure, and the crude residue recrystallized from ethanol. There was obtained $4.8 \mathrm{~g}$ of the product. The total yield was $31 \%$. After repeated recrystallization from ethanol, it melted at $151^{\circ} \mathrm{C}$.

Acknowledgements. The authors wish to express their thanks to Dr. M. Matsui, Director of Sankyo Research Laboratory for his support in carrying out their studies. They are also indebted to Mr. W. Koiwai for the preparation of some of the materials, to $\mathrm{Mr}$. K. Aizawa for measurements of ultraviolet and infrared spectra and to the members of Sankyo Co., Ltd. and of the Analytical Laboratory of the Department of Agricultural Chemistry, the University of Tokyo, for microanalytical data. 